\title{
Anti-epileptic drug harms: issues for meta-analysis
}

\author{
Catrin Tudur Smith ${ }^{*}$, Arif Shukralla², Sarah Donegan ${ }^{1}$, Karla Hemming ${ }^{3}$, Graham A Powell ${ }^{2}$, Paula Williamson ${ }^{1}$, \\ Anthony Marson ${ }^{2}$
}

From Clinical Trials Methodology Conference 2011

Bristol, UK. 4-5 October 2011

\section{Objectives}

Decisions regarding choice and dose of anti-epileptic drug (AED) are driven by considering the potential benefits of reducing seizure frequency against the potential harms of alternative AEDs. Such decisions should be made using the best available evidence, which often requires a quantitative synthesis of data from multiple randomised controlled trials (RCT). However, the systematic review and meta-analysis of harms data is hindered by problems such as inadequate reporting, heterogeneity of harms definitions, and selective reporting bias. Here we will evaluate the quality of reporting of harms data in epilepsy trials, and assess the potential added value of incorporating harms data beyond the clinical indication of epilepsy.

\section{Methods}

To evaluate the quality of reporting of harms data in RCTs of AEDs in patients with epilepsy we have undertaken a systematic review [1]. We searched MEDLINE, the Cochrane Library and the Epilepsy Group register for published trials comparing AEDs in patients with epilepsy. Each trial was assessed according to a 23 item checklist developed from the CONSORT statement for the reporting of harms in clinical trials [2]. In a separate analysis, Bayesian panoramic meta-analysis models [3] were used to pool estimates of harm across studies and across indications of epilepsy, neuropathy and headache, allowing for variation between both study and indication.

\section{Results}

For the reporting quality review we identified 152 RCTs that met the eligibility criteria. None of the trials satisfied all criteria. The mean number of criteria per trial

\footnotetext{
${ }^{1}$ North West Hub for Trials Methodology Research, Department of Biostatistics, University of Liverpool, Liverpool, UK

Full list of author information is available at the end of the article
}

was 11.3 (standard deviation 4.3, range 0 to 21 ). No improvement could be detected following publication of the CONSORT statement for harms (difference in means: 0.6 with $95 \% \mathrm{CI}(-0.9$ to 1.8$) \mathrm{p}=0.53)$. Items that were not frequently reported were; definition of adverse events (36.2\% of trials), use of a validated dictionary (21.7\% of trials), use of a validated instrument $(15.8 \%$ of trials), reporting of both number of patients and number of adverse events (19.1\% of trials) and methods for handling of recurrent events ( $7.2 \%$ of trials). In the summary of harms data, borrowing strength from other indications resulted in a more precise effect estimate, and indicate that there is evidence for some adverse events across the range of indications.

\section{Conclusion}

Reporting of harms in RCTs of AEDs is poor and has not improved since the publication of the CONSORT guidelines on the reporting of harms. To allow reliable meta-analyses of harms data, improvements to reporting quality are essential. Preliminary results suggest that harms data from AEDs prescribed for headache and neuropathy may be useful to inform the harms profile of AEDs prescribed for epilepsy.

\section{Author details \\ ${ }^{1}$ North West Hub for Trials Methodology Research, Department of Biostatistics, University of Liverpool, Liverpool, UK. ${ }^{2}$ Clinical and Molecular Pharmacology, University of Liverpool, Liverpool, UK. ${ }^{3}$ Public Health, Epidemiology and Biostatistics, University of Birmingham, Birmingham, UK. \\ Published: 13 December 2011}

\section{References}

1. Shukralla AA, Tudur Smith C, Powell GA, Williamson PR, Marson A: Reporting of adverse events in randomised controlled trials of antiepileptic drugs using the CONSORT criteria for reporting harms. Epilepsy Res 2011, accepted.

2. loannidis J, Evans S, Gotzsche P, O'Neill R, Altman D, Schulz K: Better reporting of harms in randomized trials: an extension of the CONSORT statement. Ann of Intern Med 2004, 141:781-788.
C BioMed Central 
3. Hemming K, Lilford RJ, Bowarter RJ: Pooling systematic reviews of systematic reviews: a Bayesian panoramic meta-analysis. Statistics in Medicine 2011, to appear.

doi:10.1186/1745-6215-12-S1-A11

Cite this article as: Smith et al: Anti-epileptic drug harms: issues for meta-analysis. Trials 2011 12(Suppl 1):A11.

Submit your next manuscript to BioMed Central and take full advantage of:

- Convenient online submission

- Thorough peer review

- No space constraints or color figure charges

- Immediate publication on acceptance

- Inclusion in PubMed, CAS, Scopus and Google Scholar

- Research which is freely available for redistribution

Submit your manuscript at www.biomedcentral.com/submit

() BioMed Central 